\title{
Influence of anaerobic rumen fungal inoculation on the fermentation and nutritive
}

\author{
content of selected forage silages \\ ${ }^{\mathrm{a} *}$ Idowu, O. J., ${ }^{\mathrm{b}}$ Chaudhry, A. S., ${ }^{\mathrm{c} D o l f i n g, ~ J . ~ a n d ~}{ }^{\mathrm{a} O j o, ~ V . ~ O . ~ A . ~}$ \\ ${ }^{a}$ Department of Pasture and Range Management, Federal University of Agriculture, \\ P.M.B. 2240, Abeokuta, Nigeria \\ ${ }^{b}$ School of Natural and Environmental Sciences, ${ }^{c}$ School of Civil Engineering and \\ Geosciences, Newcastle University, NE1 7RU, Newcastle upon Tyne, \\ United Kingdom \\ (20) \\ *Corresponding author: idowuoj@funaab.edu.ng or \\ o.j.bolaji@newcastle.ac.uk

\section{Abstract}

This study investigated the ability of isolated anaerobic fungi to facilitate silage fermentation characteristic and nutritive content. To achieve this, two fungal isolates out of fourteen obtained in our laboratory from sheep rumen content were selected as silage inoculants. Selection of the isolates was based on their ability to present the highest growth characteristics and they belong to the genus Orpinomyces, and Neocallimastix (as identified with microscope). The two fungi alongside the control (i.e. no fungi) were used to inoculate different silages prepared from four selected forages i.e. two tropical grasses (i.e. Andropogon gayanus- AG, Brachiaria decumbens- BD) and two temperate forages (i.e. Triticum aestivum- TA straw and Lolium perenne-LP) in order to examine their effect on fermentation (i.e. $\mathrm{pH}$ ) and nutritive content of these silages over 14 and 28 days of inoculation, respectively. The anaerobic fungal inoculated silages showed significant $(P<$ $0.05)$ improvement in quality than un-inoculated silages which was reflected in terms of increase in soluble fraction i.e. CP content; reduction in fibre content; increase in metabolites, increase in total antioxidant content (TAC); and reduction in $\mathrm{pH}$ with minimal nutrient loss. However, the rate of the anaerobic fungal improvement was influenced by the forages used for the silage and the length of inoculation. The highest and lowest increase in quality was recorded in LP and TA silages, respectively, while more extended inoculation time supported more quality improvement in the silages. The use of anaerobic fungi as inoculants improved $A G, B D, T A$ and LP silages quality through facilitation of the fermentation characteristics (i.e. pHand nutritive content).

Keywords: Nutritive content, anaerobic fungi, silage fermentation, forages, microbial additives

\section{Introduction}

Low quality forages require improvement in order for them to be properly utilised by ruminant animals for better production and performance. One of the possible ways of achieving this is by silage production. Generally, ensiling (i.e. the process that leads to the silage production) is seen as a pre-treatment method as well as forage preservation . During ensiling, the natural lactic acid bacteria that exist in the silage tend to stabilise the silage through reduction in $\mathrm{pH}$, and this is usually accompanied by fibre reduction, and increase in crude protein (CP) which can be seen as an added advantage . However, with the use of feed additives, it is expected that the added advantage is facilitated at the fermentation stage of the ensiling procedure and microbial processes in the silage are controlled through the production of specific metabolites that inhibit the 


\section{Anaerobic rumen fungi as possible improver of silage quality}

growth and activity of spoilage microbes, thus preserving and improving the silage nutrients. Among the available feed additives, microbial additives using anaerobic rumen fungi (ARF) seems promising in achieving these advantages in that its exhibit higher oxidative enzymatic function ; possesses rhizoids or mycelium which penetrates or infiltrates the plant tissues and poses no palatability threat to the animals as they exist naturally in the rumen environment. Despite all these useful attributes, the use of ARF as inoculants in silage production is still limited in improving low quality forages, as researchers are of the opinion that $\mathrm{ARF}$ cannot survive the $\mathrm{pH}$ reduction that is required for good silage production. However, investigated the use of anaerobic fungal isolates as inoculants in rice straw silage production, and $t$ established that ARF improved silage quality and that reduction in $\mathrm{pH}$ showed detrimental effect on fungal population from 30 days onward. In addition, forages used in ensiling play major roles in $\mathrm{pH}$ reduction influence on ARF due to differences in their mineral and organic acid compositions that influence their acid buffering capacity. Therefore, this current study investigated the effect of two anaerobic rumen fungal inoculants (i.e. Neocallimastix spp., and Orpinomyces spp.) on their ability to facilitate fermentation (i.e. $\mathrm{pH}$ ) and improve the nutritive value (i.e. proximate, fibre, secondary metabolites and TAC) of silages using four different forages i.e. Andropogon gayanus, Brachiaria decumbens (tropical forages) and Triticum aestivum straw and Lolium perenne (temperate forages) over 14 and 28 days, respectively.

\section{Materials and methods Anaerobic rumen fungi}

In preparation for this experiment, fourteen anaerobic fungi were isolated from sheep rumen fluid in our laboratory (School of
Agriculture, Food and Rural Development, Newcastle University, UK) and identified up to the genus level using light and fluorescence microscopy (epifluorescence microscope, Nikon Eclipse Ci, CoolLED pE-300-W, Japan). Two isolates with the highest growth characteristics were then selected, multiplied and stored with $10 \%$ glycerol in relevant $25 \mathrm{~mL}$ serum bottles fitted with butyl rubber septa and sealed with metal crimps at $-20^{\circ} \mathrm{C}$ in a walk in freezer. On anticipation for the experiment, the cultures in bottles were thawed at $4^{\circ} \mathrm{C}$ and then kept in a water bath at $39^{\circ} \mathrm{C}$ for $12 \mathrm{hrs}$. An inoculum of $4 \%$ (vol $/ \mathrm{vol})$ was aseptically injected, under $\mathrm{CO}_{2}$ atmosphere, into $25 \mathrm{ml}$ of the freshly prepared Orpin's medium (i.e. clarified rumen fluid and complex medium) as reported by . This was then placed at $39^{\circ} \mathrm{C}$ in an incubator Scientific laboratory supplies incubator, INC1253 for 4 - 5 days in order to get the inoculum for each of the forage samples used.

\section{Preparation of forage substrates and inoculation with anaerobic fungi}

The samples consisted of 4 selected forages which includes 2 tropical forages (AG and $\mathrm{BD}$ ) and 2 temperate forages (TA straw and LP). About $5 \mathrm{~g}$ of each dried and ground substrate $(<2-\mathrm{mm}$ particle size $)$ of each of the forages was accurately weighed into $250 \mathrm{ml}$ bottles and rehydrated with $10 \mathrm{ml}$ of the Orpin's medium without antibiotics or vitamins. The bottles were fitted with butyl rubber caps, sealed with metal crimps, and autoclaved at $121^{\circ} \mathrm{C}$ for $15 \mathrm{mins}$. The prepared serum bottles were inoculated with $5 \mathrm{~mL}$ of 5 days old, well grown anaerobic fungal culture in a broth by aseptically injecting the fungi into the bottles under $\mathrm{CO}_{2}$ atmosphere, using a sterile syringe and a needle, and incubated at $39^{\circ} \mathrm{C}$ for 14 and 28 days, respectively. This was replicated four times. Additional flasks, each containing $5 \mathrm{ml}$ of autoclaved Orpin's medium and substrates but without fungal inoculations, were also prepared as controls. At the end of each incubation time, 


\section{Idowu, Chaudhry, Dolfing and Ojo}

Isolate 1: Orpinomyces sp (polycentric, multiflagellate, filamentous)
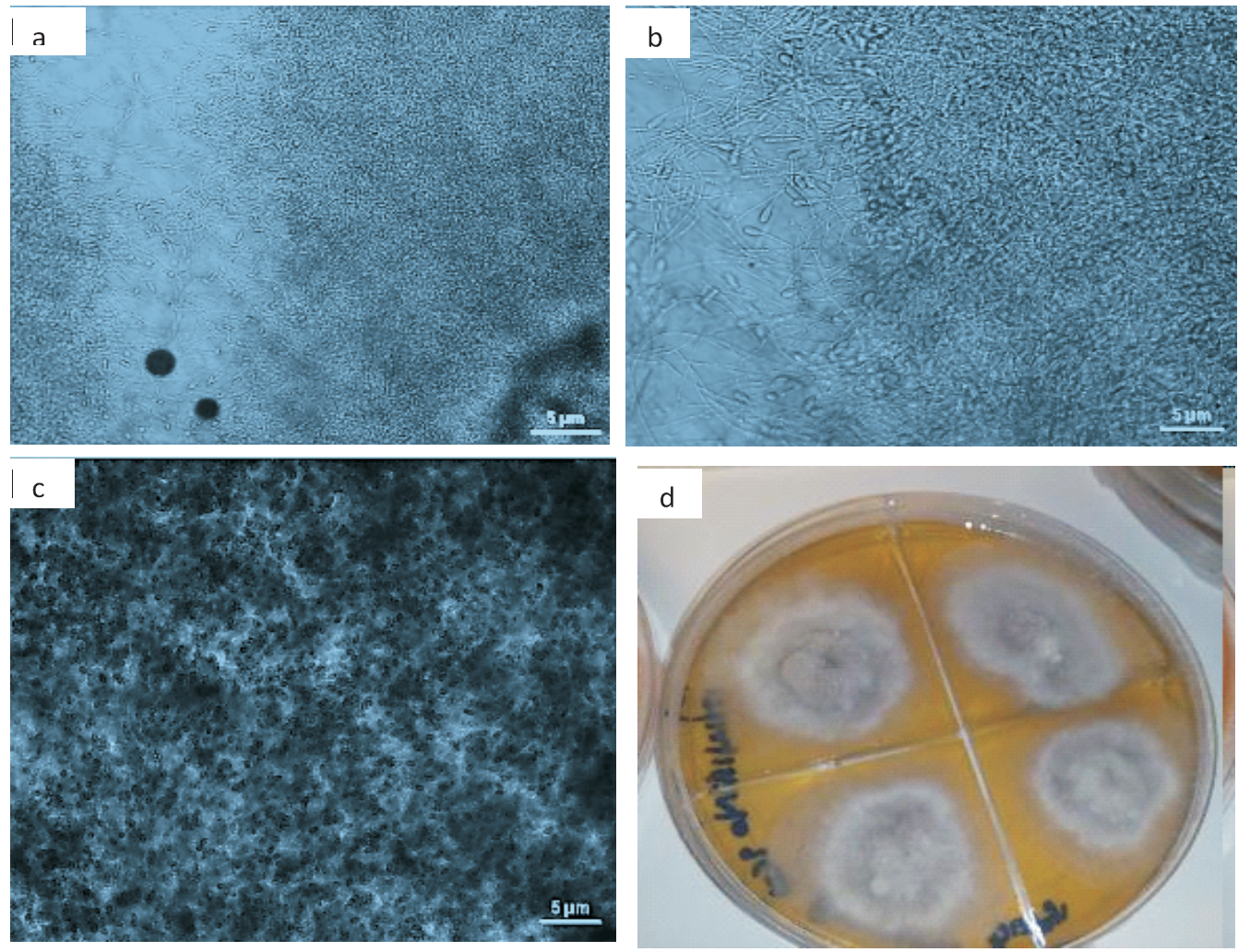

Figure1 a) Hyphae and spore of Isolate 1 (20X); b) Hyphae and spore of Isolate 1 $(40 X)$; c) Spore of Isolate $1(20 X)$ and d) Isolate 1 on plate

$\mathrm{pH}$ was determined and were subsequently processed. The contents of each bottle were filtered through tarred whatman filter paper no. 1 and the filtrates were centrifuged at $10,000 \mathrm{rpm}(12800 \mathrm{~g})$ in a refrigerated $\left(4^{\circ} \mathrm{C}\right)$ centrifuge for $20 \mathrm{mins}$. The liquid part was used for the determination of laccase enzymatic activity, while the sample on the filter paper was dried at $60^{\circ} \mathrm{C}$ in preparation for the subsequent chemical analyses. Losses of dry matter and other nutrients as influenced by fungal inoculation were calculated as the differences in absolute weights between the respective controls (un-inoculated substrate) and inoculated substrates, and the results were presented as per cent of the control.

\section{pH and chemical analyses}

The $\mathrm{pH}$ was determined with the aid of a $\mathrm{pH}$ meter (Oakton Acorn series pH 6 metre, Sigma-Aldrich) and the dried silage samples were used for chemical analyses. The analyses was done in quadruplicate for dry matter (DM), Organic matter (OM), and Ash using methods. Nitrogen values were obtained using an Elementar vario macro cube (Elementar, Hanau Germany). The crude protein (CP) content was then calculated $(\mathrm{N} x$ 6.25). Neutral Detergent Fibre (NDF), and Acid Detergent Fibre (ADF) using the methods of. Total phenolic (TP) and total tannin (TT) contents were measured using modified Folin-Ciocalteu method. Both TP and TT were expressed as 


\section{Anaerobic rumen fungi as possible improver of silage quality}

Isolate 2: Neocallimaxtix sp (monocentric, multiflagellate, filamentous)
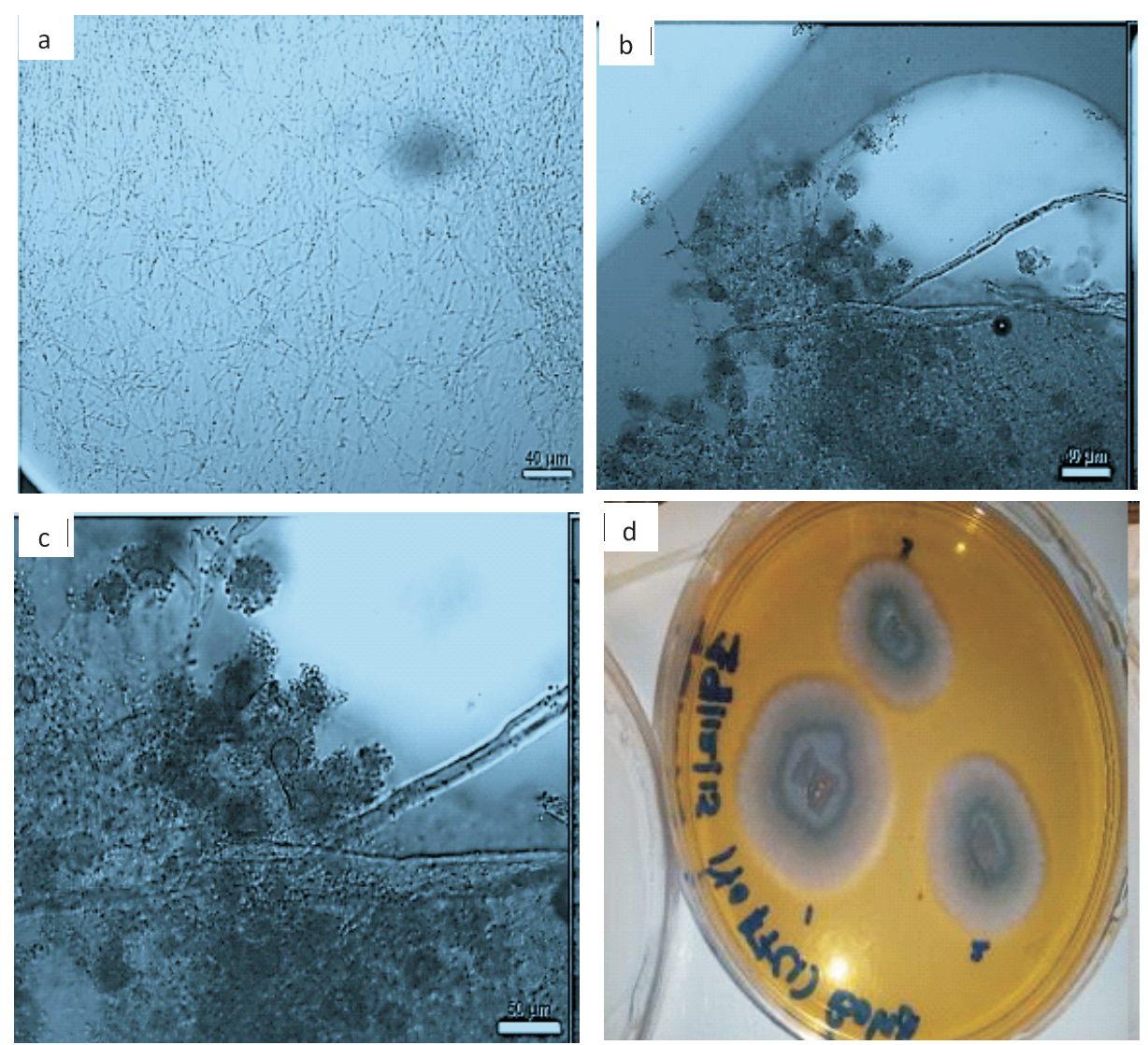

Figure 2 a) Hyphae of Isolate 2 (20X); b) Hyphae and spore of Isolate 2 (20X); c) Hyphae and Spore of Isolate $2(40 x)$ and d) Isolate 2 on plate

tannic acid equivalents. TAC of the samples were determined according to the Ferric Reducing Antioxidant Power assay and results obtained were then expressed as $\mu \mathrm{mol} \mathrm{Fe}$ (II)/g dry weight of the sample.

\section{Statistical analysis}

Two- way ANOVA using the Generalized Linear Model procedure in Minitab 16 software was used to determine the effects of fungal inoculants, forage silages and their interaction on the $\mathrm{pH}$ and chemical composition at each incubation time (i.e. 14 and 28 days). The effects were declared significant if $\mathrm{P}<0.05$. The means were separated using the Tukey's test for significance at $\mathrm{P}<0.05$.

\section{Results}

The anaerobic rumen fungal inoculants had a significant reducing effect on $\mathrm{pH}$ values of A. gayanus (AGS), B. decumbens (BDS), L. perenne (LPS) and T. aestivum (TAS) silages. The reducing effect increased with increase in the ensiling period both in the inoculated and uninoculated silages but was not rapid. The fungi used as inoculants produced a similar reducing effect on the $\mathrm{pH}$ values of all silages. The ensiled forages varied in their $\mathrm{pH}$ reduction and followed this trend: LPS 


\section{Idowu, Chaudhry, Dolfing and Ojo}

Table 1: Effects of anaerobic rumen fungal inoculants on $\mathrm{pH}$ values of each forage silage during ensiling periods

\begin{tabular}{llllll}
\hline & \multicolumn{5}{c}{ Fungi } \\
Ensiling time (days) & Control & Neocallimastix sp. & Orpinomyces sp. & SEM & P value \\
\hline B. decumbens silage & & & & & \\
14 & $6.04^{\mathrm{a}}$ & $5.80^{\mathrm{b}}$ & $5.83^{\mathrm{b}}$ & 0.04 & $<0.0002$ \\
28 & $5.96^{\mathrm{a}}$ & $5.71^{\mathrm{b}}$ & $5.71^{\mathrm{b}}$ & 0.04 & $<0.0001$ \\
A. gayanus silage & & & & & \\
14 & $6.00^{\mathrm{a}}$ & $5.91^{\mathrm{b}}$ & $5.90^{\mathrm{b}}$ & 0.02 & $<0.0005$ \\
28 & $5.95^{\mathrm{a}}$ & $5.81^{\mathrm{b}}$ & $5.74^{\mathrm{b}}$ & 0.03 & $<0.0002$ \\
L. perenne silage & & & & & \\
14 & $5.37^{\mathrm{a}}$ & $5.27^{\mathrm{b}}$ & $5.28^{\mathrm{b}}$ & 0.02 & $<0.0091$ \\
28 & $5.34^{\mathrm{a}}$ & $5.19^{\mathrm{b}}$ & $5.16^{\mathrm{b}}$ & 0.03 & $<0.0003$ \\
T. aestivum silage & & & & & \\
14 & $6.28^{\mathrm{a}}$ & $6.16^{\mathrm{b}}$ & $6.19^{\mathrm{b}}$ & 0.01 & $<0.0015$ \\
28 & $6.21^{\mathrm{a}}$ & $6.11^{\mathrm{a}}$ & $6.12^{\mathrm{a}}$ & 0.03 & $<0.247$ \\
Pooled SEM & 0.07 & 0.07 & 0.07 & & \\
P value & $<0.0001$ & $<0.0001$ & $<0.0001$ & & \\
\hline
\end{tabular}

Means with different letters in the same row are significantly different; SEM: standard error of means

The interactive effects of forage silage and fungal inoculants produced a significant $(\mathrm{P}$ $<0.05$ ) effect on the proximate and fibre fractions composition of the silages after 14 and 28 days of inoculation respectively (Table 2). The fungal inoculants reduced the fibre contents (i.e. NDF, ADF) but increased the $\mathrm{CP}$ and ash contents but both the reduction and increment was not drastic. The increase in the $\mathrm{CP}$ content was significantly $(\mathrm{P}<0.05)$ different from the control in the tropical forage silages as the inoculation time increased. The anaerobic fungi had preferences for different silages for possible improvement and this varied with increase in inoculation time. At early inoculation time, Neocallimastix sp., improved tropical forage silages while the opposite was recorded in temperate forage silages. However with increase in inoculation time their preferences changed, AGS and LPS (Neocallimastix sp), BDS (Orpinomyces sp) and TAS (similar preference)

The secondary metabolites contents and TA contents of the ensiled forages inoculated with anaerobic rumen fungi over two incubation times (i.e. 14 and 28 days) are shown in Fig 1: a to c respectively. The fungi used for ensiling varied in their forage preferences for possible improvement when compared with the control. Both fungi reduced TP content of all the silages; Orpinomyces and Neocallimastix sp. increased and reduced the TT content of most of silages respectively; and both fungi reduced and increased the TAC of temperate and tropical forage silages respectively. However, with increase in inoculation time, both fungal inoculation led to TP and TT contents increase in most of the ensiled forages while their effect on the TAC varied.

Figure a-c show the secondary metabolites content of forages with 3 different fungal treatments (Control, Neocallimastix and Orpinomyces) respectively for 14 and 28 days. The interactive effects of forage silage and anaerobic rumen fungal inoculants on nutrient loss (+) / gain (-) \% of ensiled forages after 14 and 28 days of inoculation are presented in Table 3. In general, the fungal inoculants led to minimal nutrient 


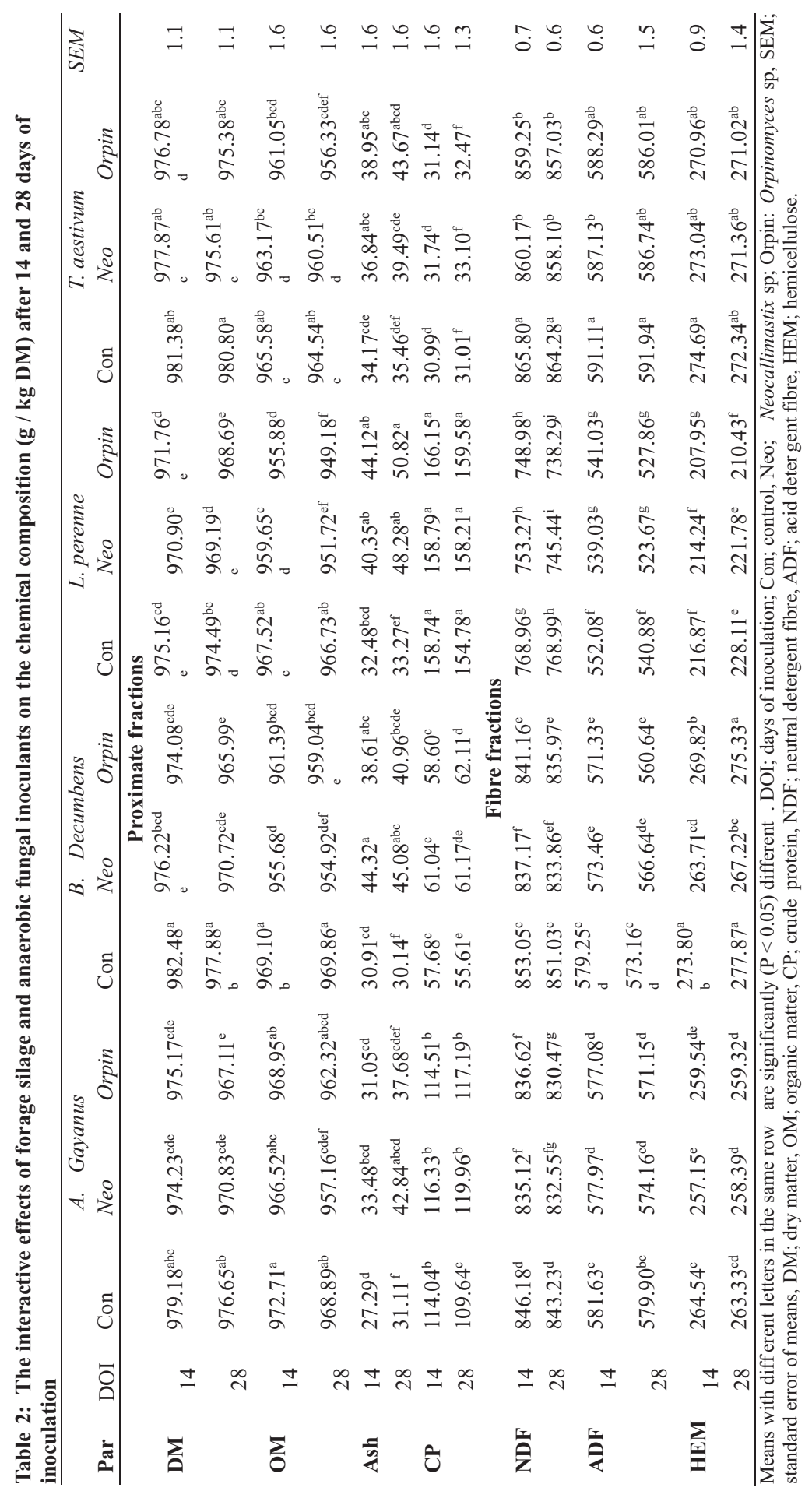




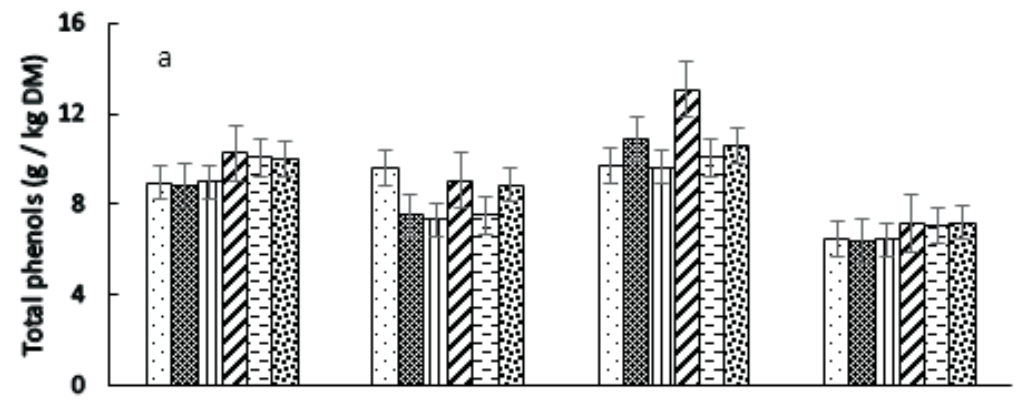

\section{$\square$ 14D Control \\ 14D Neocallmastix \\ 口 14D Orphomyces \\ $\square 280$ Control \\ $\square 280$ Neocallmastix \\ ⿶ 280 Orphomyces}

A. gayanus

B. decumbens

L. perenne

T. aestivum

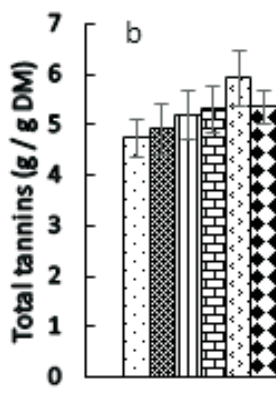

A. gayanus

B. decumbens

L. perenne

T. aestivum

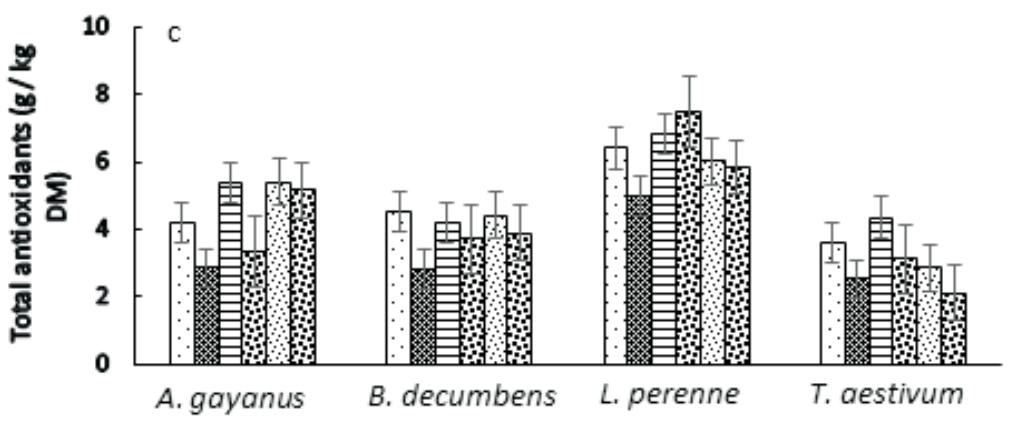

Q140 Control

因 14D Neocallimastix

$\square 140$ Orpinomyces

tet 28D Control

글 280 Neocallmastix

¿28D Orpinomyces losses $(<5 \%)$ in fibre contents and hem; higher ash gain; minimal CP gain $(<10 \%)$ minimal TP loss; and TT and TAC gain or loss in most of the forage silages. The influence that the fungal inoculation had on nutrient loss / gain recorded in the silages varied with the forage source and inoculation time. Neocallimastix sp. recorded more nutrient loss / gain in tropical forages while the opposite was recorded with temperate forages. However, with increase in inoculation time, the fungi preference for silage changed in that Orpinomyces sp. recorded more nutrient loss / gain in most of the forage except in BDS. Neocallimastix sp led to TT gain while Orpinomyces sp led to TT loss in most of the silages respectively. The fungal inoculation led to TAC loss and gain in both temperate and tropical forage silages respectively. 
Anaerobic rumen fungi as possible improver of silage quality

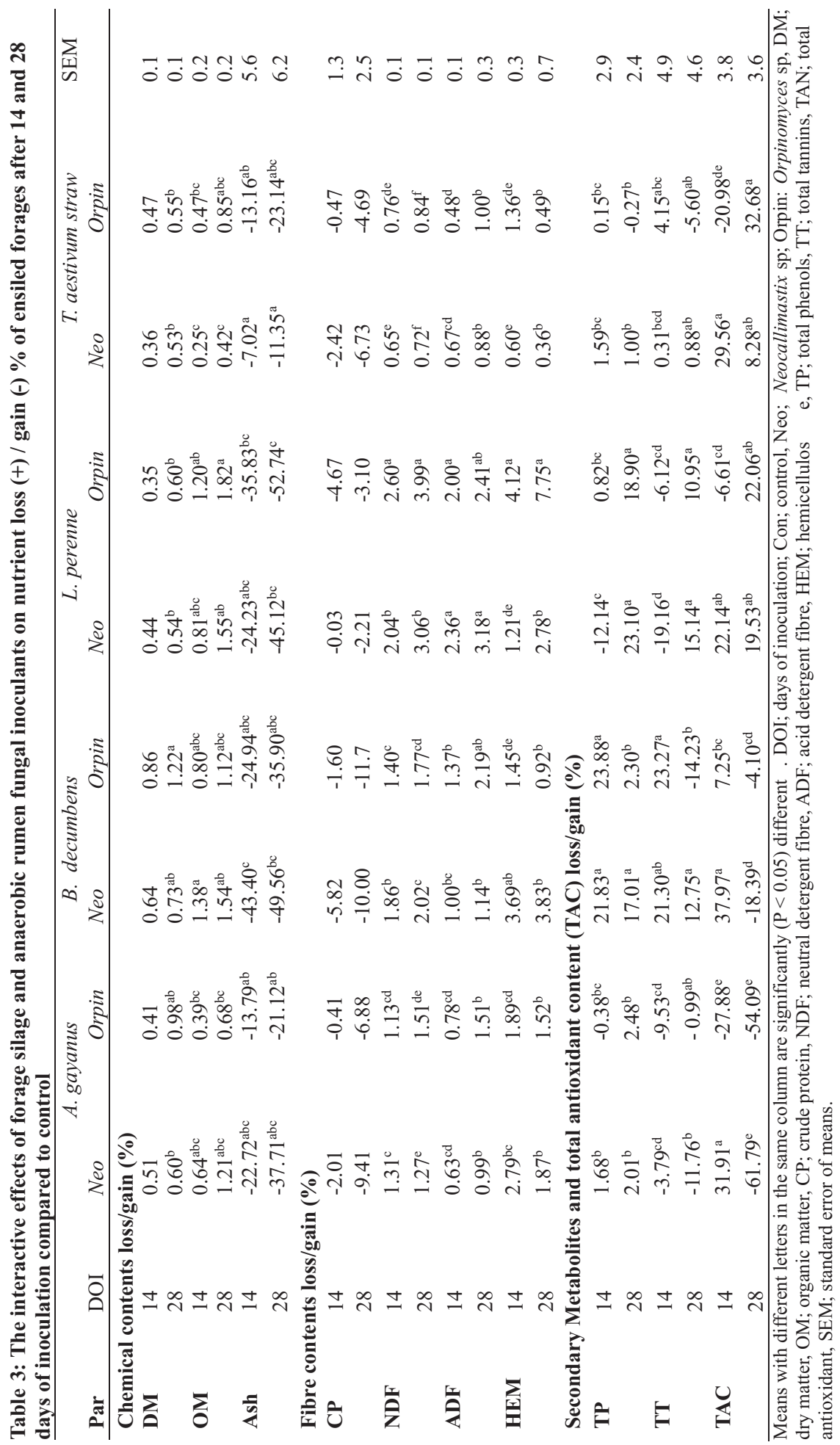




\section{Idowu, Chaudhry, Dolfing and Ojo}

\section{Discussion}

The study aimed to improve the quality of the selected forages by ensiling them with anaerobic rumen fungal inoculants, so as to facilitate the fermentation stage of the silage procedure. The fungal inoculants used minimally improved the nutritive quality and the fermentation rate of the forage silages with lowered $\mathrm{pH}$, increased $\mathrm{CP}$ content, increased fibre degradation, increased metabolite content, and increased total antioxidant content of the tropical forages, with minimal nutrient losses in the silages. The reduction in $\mathrm{pH}$ by anaerobic rumen fungal inoculants in this study indicates that the inoculants are facilitating the ensiling process. It also reflects that the fermentation of sugars or water-soluble carbohydrates in anticipation for lactic acid production is taken place as the lactic acid lowers the $\mathrm{pH}$ to aid in the silage stability . The further reduction in $\mathrm{pH}$ of the silages with increase in inoculation time, although not drastic is an indication that the $\mathrm{pH}$ is still supporting the fungal activity. This supports the findings of , however the reduction was not as drastic as their report. This could be attributed to the availability of watersoluble carbohydrates (WSC) and the acid buffering capacity of the forage. Forages with less potential of producing WSC and high buffering capacity tends to limit rapid $\mathrm{pH}$ reduction. The variation recorded in the $\mathrm{pH}$ value of the silages might also be attributed to their acid buffering capacity and availability of structural carbohydrate.

The increased $\mathrm{CP}$ content and fibre reduction in the ensiled forages inoculated with ARF is evidence that the fungal inoculants are exhibiting their proteolytic and hydrolytic enzymatic function. The increased CP content could be as a result of the solubility of structural carbohydrates that facilitated fungal growth in anticipation for the degradation of all dietary nitrogen content needed for protein synthesis or can be attributed to the contributing effect of fungal biomass. The insignificant $\mathrm{CP}$ increase obtained in some of the forage silages inoculated with ARF was similar to that reported by. This might be that the contributions of fungal biomass towards total CP content was not significant enough. The few cases where a significant increase in $\mathrm{CP}$ content was recorded was in the $\mathrm{C}_{4}$ (i.e. tropical plants in hot climate) plants. This supports the statement that $\mathrm{C}_{4}$ plants generally do contain lower $\mathrm{CP}$ contents, but they are more efficiently utilised by microbes than $\mathrm{C}_{3}$ (i.e. temperate plants in cold climate) plants .

The increased fibre degradation in inoculated ensiled forages was in agreement with previous findings that most anaerobic rumen fungi were capable of degrading fibre, due to their enzymatic activities and the ability of their mycelium/rhizoids or bulbous hold fast to penetrate structural carbohydrates . It is also an indication that the fungi are exhibiting their fibrolytic activity in decomposing the structural carbohydrates . The variation recorded in the preferences for the substrate by fungal inoculants for fibre degradation can be attributed to fungal strains and forage chemical composition, as different fungal strains vary in their fibrolytic roles, while forage chemical composition influences their ability to support the growth and activity of fungi . The reduced fibre contents in all the forage silages was in support of the findings of , where some of the fibrolytic enzymes function of Neocallimastix investigated increased with increase in incubation time. The less reduction in fibre in the forage silages, despite fungal inoculation might be attributed to the maturity stage of the forages, as highly matured forages contain more structural carbohydrates that can negatively influence the achievement of 


\section{Anaerobic rumen fungi as possible improver of silage quality}

good quality silage. This supports the report of that high-quality silages using tropical forages are difficult to produce, due to their low water-soluble carbohydrates and presence of natural lactic acid bacteria.

The continued increase in metabolites content in almost all forage silages inoculated with Orpinomyces sp., with increase in inoculation time in tropical forages, were in agreement with the findings that the use of additives in controlling the microbial silage processes leads to the production of specific metabolites that are involved in the inhibition of the growth and activity of spoilage microbes (e.g. Clostridium sp.) in the silage. However, the continued reduction in metabolite contents recorded in almost all forage silages inoculated with Neocallimastix sp. was not expected. The increased TAC with increase in inoculation time in the tropical forage silages might be because the fungus was producing TAC as its specific metabolite. The increased TAC has other benefits, in that it is involved in maintaining a balance in the animal health and immune system. The variation in time at which each fungal inoculant was supporting metabolites and $\mathrm{TAC}$, can be attributed to the fact that fungi vary in the rate and fermentation time in which they achieve lignocellulose degradation from which phenolic compounds are being released.

The minimal energy loss (i.e. $<5 \%$ ) and CP gain in the inoculated forage silages are an indication that the nutrients are well preserved and not utilised by spoilage microbes, which is an attribute of good quality silage. In addition, the goal of ensiling was also achieved, which was to minimise nutrient degradation by spoilage microbes and conserve a significant amount of digestible energy and protein for the ruminant animals. However, the higher metabolites loss with the use of Neocallimastix sp., which was complemented with higher TAC gain, was not expected. It might be that the fungus was utilising the metabolites towards increasing the TAC capacity of forages, therefore using the TAC as its specific metabolite that is needed for the inhibition of spoilage microbes .

\section{Conclusion}

The supplementation of the isolated anaerobic rumen fungi as silage inoculants minimally improved the silage quality of the forages through reduction in $\mathrm{pH}$ and fibre content, as well as increased $\mathrm{CP}$ content, metabolites contents especially by Orpninomyces sp., and total antioxidant contents especially by Neocallimastix sp., respectively with corresponding minimal nutrient loss. Further research is, therefore, necessary to obtain an efficient nutrient utilisation by animals consuming these silages by introducing the forage silages into the rumen environment, with or without the isolated ARF to manipulate the rumen microbial ecosystem for an increase in the fermentation rate. In addition, more research is required to improve the fermentation rate of the ARF when used as inoculants along with natural lactic acid bacteria (e.g. Lactobacillus plantarium and L. casei) in silage procedures over a short period of time.

\section{References}

Abrão, F. O., Duarte, E. R., Freitas, C. E. S., Vieira, E. A., Geraseev, L. C., da Silva-Hughes, A. F., Rosa, C. A. and Rodrigues, N. M. 2014. 'Characterization of fungi from ruminal fluid of beef cattle with different ages and raised in tropical lignified pastures', Current Microbiology, 69(5), pp. 649-659.

AOAC 1990. 'Official methods of analysis. ', Association of official Analytical Chemist, 14th Edition, Washington, 


\section{Idowu, Chaudhry, Dolfing and Ojo}

D. C. , p. 2044pp.

Benzie, I. F. F. and Strain, J. J. 1996. 'The ferric reducing ability of plasma (FRAP) as a measure of "antioxidant power": the FRAP assay', Analytical Biochemistry, 239(1), pp. 70-76.

Chew, B.P. (1995) 'Antioxidant vitamins affect food animal immunity and health', The Journal of Nutrition, 125(suppl_6),pp. 1804S-1808S.

da Silva, R. R., Pedezzi, R. and Souto, T. B. 2017 . 'Exploring the b i o p r o s p e c i n a n d biotechnological potential of white$\mathrm{rot}$ a n d a n e r o b i c Neocallimastigomycota fungi: peptidases, esterases, and lignocellulolytic enzymes', Applied Microbiology and Biotechnology, 101(8), pp. 3089-3101.

Denman, S. E. and McSweeney, C. S. 2006. 'Development of a real-time PCR assay for monitoring anaerobic fungal and cellulolytic bacterial populations within the rumen', FEMS Microbiology Ecology, 58(3), pp. 572-582.

Gordon, G. L. and Phillips, M. W. 1989. 'Degradation and utilization of cellulose and straw by three different anaerobic fungi from the ovine rumen', Applied and Environmental Microbiology, 55(7), pp. 1703-1710.

Gordon, G. L. R. and Phillips, M. W. 1998. 'The role of anaerobic gut fungi in ruminants', Nutrition Research Reviews, 11(1), pp. 133168.

Ho, Y. W. and Abdullah, N. 1999. 'The role of rumen fungi in fibre digestion', Asian Australasian Journal of Animal Sciences, 12, pp. 104-112.

Khota, W., Pholsen, S., Higgs, D. and Cai, Y. 2016. 'Natural lactic acid bacteria population of tropical grasses and their fermentation factor analysis of silage prepared with cellulase and inoculant', Journal of Dairy Science, 99(12), pp.9768-9781.

Khota, W., Pholsen, S., Higgs, D. and Cai, Y. 2018. 'Comparative analysis of fermentation characteristics and in vitro digestibility of tropical silage prepared with Acremonium and Tricoderma producing cellulases', Asian-Australasian Journal of Animal Sciences.

Lee, S. M., Guan, L. L., Eun, J. S., Kim, C. H., Lee, S. J., Kim, E. T. and Lee, S. S. 2015. 'The effect of anaerobic fungal inoculation on the fermentation characteristics of rice straw silages', Journal of Applied Microbiology, 118(3), pp. 565-573.

Leis, S., Dresch, P., Peintner, U., Fliegerová, K., Sandbichler, A. M., Insam, H. and Podmirseg, S. M. 2014. 'Finding a robust strain for biomethanation: anaerobic fungi (Neocallimastigomycota) from the Alpine ibex (Capra ibex) and their associated methanogens', Anaerobe, 29, pp. 34-43.

Muck, R. and Kung Jr, L. 1997. 'Effects of silage additives on ensiling', Silage: Field to feedbunk, pp. 187199.

Neureiter, M., dos Santos, J. T. P., Lopez, C. P., Pichler, H., Kirchmayr, R. and Braun, R. 2005. 'Effect of silage preparation on methane yields from whole crop maize silages', Proceedings of the 4th International Symposium on Anaerobic Digestion of Solid Waste, 31, pp. 109-115.

Paul, S. S., Kamra, D. N., Sastry, V. R. B., Sahu, N. P. and Agarwal, N. 2004. 'Effect of anaerobic fungi on in vitro feed digestion by mixed rumen microflora of buffalo', 
Reproduction Nutrition Development, 44(4), pp.313-319.

Pholsen, S., Khota, W., Pang, H., Higgs, D. and C a i, Y. 2016 . 'Characterization and application of lactic acid bacteria for tropical silage preparation', Animal Science Journal, 87(10), pp. 1202-1211.

Puniya, A. K., Goel, G., Griffith, G. W., Nagpal, R., Sehgal, J. P., Singh, K. and Puniya, M. 2014. 'Anaerobic rumen fungi: potential and applications', in Academic World International.

Rezaeian, M., Beakes, G. W. and Chaudhry, A. S. 2005. 'Relative fibrolytic activities of anaerobic rumen fungi on untreated and sodium hydroxide treated barley straw in in vitro culture', Anaerobe, 11(3), pp. 163-175.

Silva, C., Bass, M., Hancock, D. and Stewart Jr, R. 2018. 'Impact of Different Maturity Stages on Yield and Quality of Ensiled Johnsongrass (Sorghum halepense (L.) Pers)', Journal of Animal Science, 96, pp. 11-12.

Singleton, V. L. and Rossi, J. A. 1965. 'Colorimetry of total phenolics with phosphomolybdic-phosphotungstic acid reagents', American journal of Enology and Viticulture, 16(3), pp. 144-158.

Theodorou, M. K., Brookman, J. and Trinci, A. P. J. 2005. 'Anaerobic fungi', in Methods in Gut Microbial Ecology for Ruminants. Springer, pp. 55-66.

Van Soest, P. J. 1994. Nutritional ecology of the ruminant. Cornell University Press.
Van Soest, P. J., Robertson, J. B. and Lewis, B. A. 1991. 'Methods for dietary fiber, neutral detergent fiber, and nonstarch polysaccharides in relation to animal nutrition', Journal of dairy science, 74(10), pp. 35833597.

Wilson, J. R., Taylor, A. O. and Dolby, G. R. 1976. 'Temperature and atmospheric humidity effects on cell wall content and dry matter digestibility of some tropical and temperate grasses', New Zealand Journal of Agricultural Research, 19(1), pp. 41-46.

Yue, Q., Yang, H. J., Cao, Y. C., Zhang, D. F., Jiang, Y. H. and Wang, J. Q. 2009. 'Feruloyl and acetyl esterase production of an anaerobic rumen fungus Neocallimastix sp. YQ2 effected by glucose and soluble nitrogen supplementations and its potential in the hydrolysis of fibrous feedstuffs', Animal Feed Science and Technology, 153(3), pp. 263277.

Zhang, S. J., Chaudhry, A. S., Ramdani, D., Osman, A., Guo, X. F., Edwards, G. R. and Cheng, L. 2016. 'Chemical composition and in vitro fermentation characteristics of high sugar forage sorghum as an alternative to forage maize for silage making in Tarim Basin, China', Journal of Integrative Agriculture, 15(1), pp. 175-182

Received: $17^{\text {th }}$ October, 2019 Accepted: $27^{\text {th }}$ January, 2020 